\title{
WADAH KOMUNITAS AGRIKULTUR DI KEBAYORAN LAMA
}

\author{
Maria Magdalena Venny Florentina ${ }^{1)}$, Tatang Hendra Pangestu ${ }^{2)}$ \\ 1) Program Studi S1 Arsitektur, Fakultas Teknik, Universitas Tarumanagara, mariavennyyy@gmail.com \\ 2) Program Studi S1 Arsitektur, Fakultas Teknik, Universitas Tarumanagara, tatang_pangestu@hotmail.com
}

\begin{abstract}
Abstrak
Pangan merupakan kebutuhan dasar manusia yang paling utama. Berdasarkan data dari PBB, populasi di bumi pada tahun 2050 diperkirakan akan mencapai 9,1 milyar jiwa, sehingga dunia harus memproduksi 70\% makanan lebih banyak dibandingkan dengan hari ini untuk menyediakan makanan bagi seluruh jiwa yang ada di bumi. Apabila kesediaan pangan ini tidak dapat terpenuhi, maka akan terjadi krisis pangan. Dengan adanya konsep program 'Urban Farming' atau pertanian kota inilah yang akan membantu permasalahan pangan dan juga dapat menjadi suatu wadah sosial untuk kegiatan interaksi sosial warganya. Proyek Wadah Komunitas Agrikultur yang berada di Kebayoran Lama ini merupakan fasilitas yang menggabungkan fungsi ruang publik berbasis komunitas, edukasi dan juga komersil. Proyek ini memanfaatkan konteks kawasan yang terkenal dengan kawasan hijaunya dan di analisa melalui metode 'Urban Analysis' yang digunakan untuk mempelajari keadaan kawasan di sekitar tapak sehingga terdapat point-point penting yang membentuk suatu wujud arsitektur. Program pada bangunan ini mengutamakan tentang bagaimana warga di sekitar kawasan dapat memproduksi makanannya sendiri mulai dari langkah kecil yaitu menanam makanan sehari-hari seperti sayuran dan juga buah-buahan. Proyek ini membantu warga sekitar agar menambah pasokan pangan bagi kawasan dan juga mengedukasi warganya untuk hidup sehat sekaligus produktif. Dengan memanfaatkan konsep hijau pada bangunan seperti green facade, green roof, rain garden, zero run-off, dll proyek ini akan mencapai konsep bangunan berkelanjutan sehingga membantu kota agar menjadi kota yang lebih sehat.
\end{abstract}

Kata kunci: hijau; pangan; pertanian

\begin{abstract}
Food is the most basic human need. Based on data from the United Nations, the population on earth in 2050 is estimated to reach 9.1 billion people, so the world must produce $70 \%$ more food than today to provide food for all human on earth. If this food availability cannot be fulfilled, a food crisis will occur. With the concept of the program 'Urban Farming' that will help the problem of food and can also become a community for social interaction activities of its citizens. The Agricultural Community Space Project in Kebayoran Lama is a facility that combines community, educational and commercial functions of public space. This project utilizes the context of the region which is famous for its green areas and is analyzed through the 'Urban Analysis' method which is used to study the condition of the area around the site so that there are important points that form an architectural form. The program in this building focuses on how residents around the area can produce their own food starting from the small steps of growing daily foods such as vegetables and fruits. This project helps local residents to increase food supply for the region and also educates citizens to live healthy and productive lives. By utilizing green concepts in buildings such as green facades, green roofs, rain gardens, zero run-offs, etc. this project will achieve the concept of sustainable buildings so that it helps cities to become healthier cities.
\end{abstract}

Keywords: farming; food; green 


\section{PENDAHULUAN}

Kota-kota besar di Indonesia seperti Jakarta, dalam memenuhi kebutuhan konsumsi warganya, memerlukan pasokan volume pangan yang tidak sedikit dari daerah lain. Karena terbatasnya lahan pertanian di Jakarta yang sekarang sudah dibangun dengan gedung-gedung tinggi, hal ini menjadikan Jakarta tidak mempunyai pasokan pangan dari daerah sendiri. Dengan terbatasnya jumlah produksi pangan di Kota Jakarta yang tidak sebanding dengan jumlah penduduk, Jakarta tidak mampu memenuhi konsumsi warganya.

Dengan adanya kegiatan Urban Farming di tengah masyarakat urban, hal ini dapat membantu masalah keterbatasan pangan di masa yang akan datang dan juga dapat meningkatkan interaksi sosial dengan sesama masyarakat. Program ini memberikan ruang hijau dan rekreasi, memberikan penghematan dan manfaat ekologis bagi kota, membantu pembentukkan komunitas dan memiliki potensi sebagai sumber baru pembangunan ekonomi. Dengan langkah kecil ini, kita menumbuhkan akar rumput untuk menanamkan hubungan dalam masyarakat, dimulai dengan mengedukasi masyarakat mengenai pangan, menjembatani batas antara konsumen dan produsen, serta menjadikan produksi/ distribusi makanan menjadi bagian dari kehidupan urban.

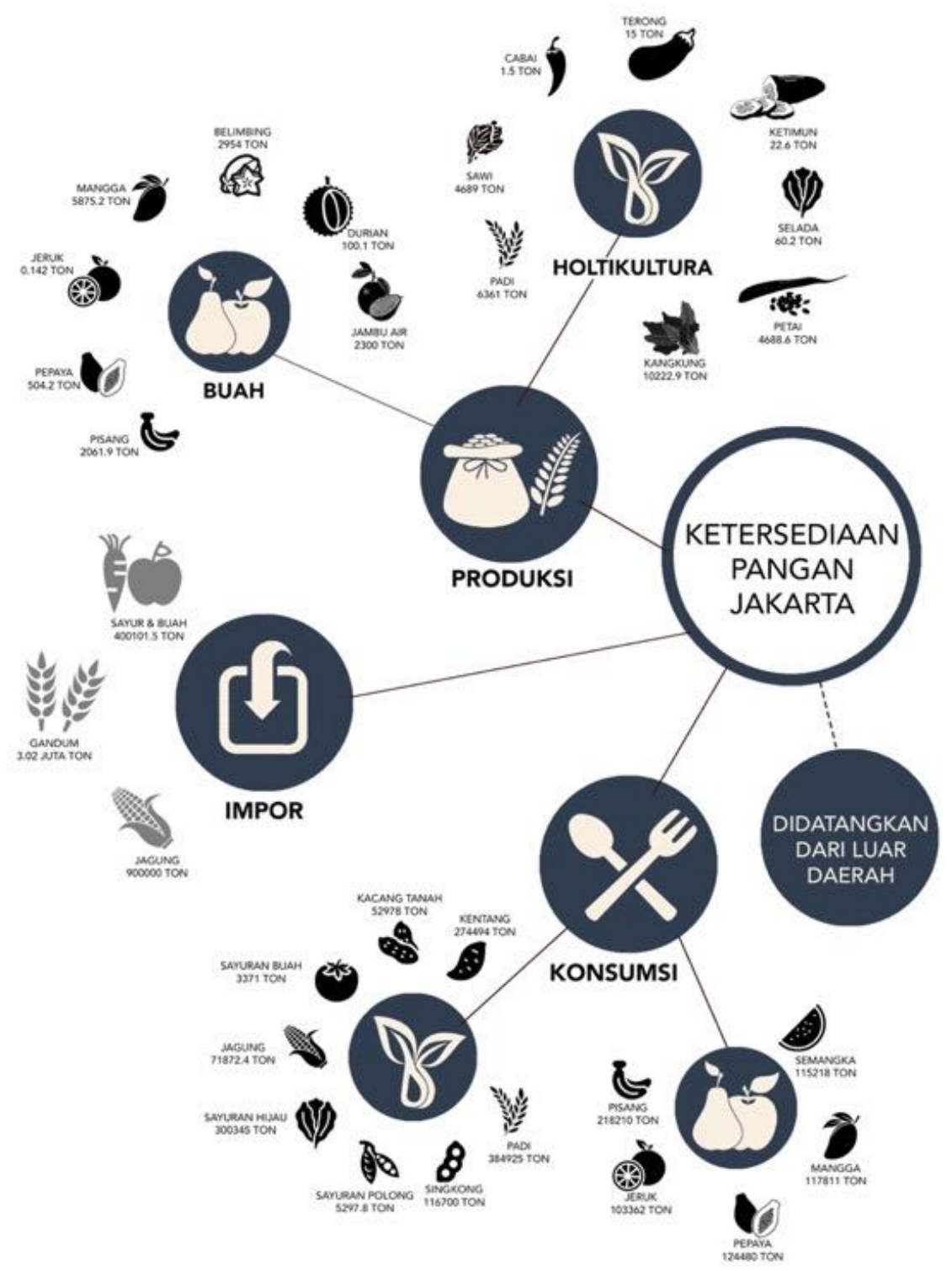

Gambar 1. Kebutuhan dan Produksi Pangan Jakarta Sumber: Dipetakan menurut data BPS 2018 


\section{KAJIAN LITERATUR}

\section{Third place}

Pengertian Place bukanlah sesuatu yang abstrak atau sekedar berupa konsep, tetapi Place adalah sebuah fenomena kehidupan yang mengandung unsur pengalaman langsung, mempunyai arti dan merupakan sesuatu yang nyata yang didalamnya terdapat aktivitas yang terjadi terus menerus. Keberadaan Place sangatlah penting karena merupakan sumber dari sebuah identitas yang menunjukkan eksistensi individu maupun komunitas, bahkan lebih dari itu, place mempunyai hubungan yang emosional sangat dalam dan psikologi, baik itu seseorang maupun komunitas. Menurut Ray Ouldenburg, The Problem of Place In America, Istilah Third place adalah istilah yang umum untuk menandakan tempat-tempat publik yang diadakan secara tetap, sukarela, informal untuk kegiatan informal, seperti berkumpul bersama keluarga atau teman.

\section{Open Architecture}
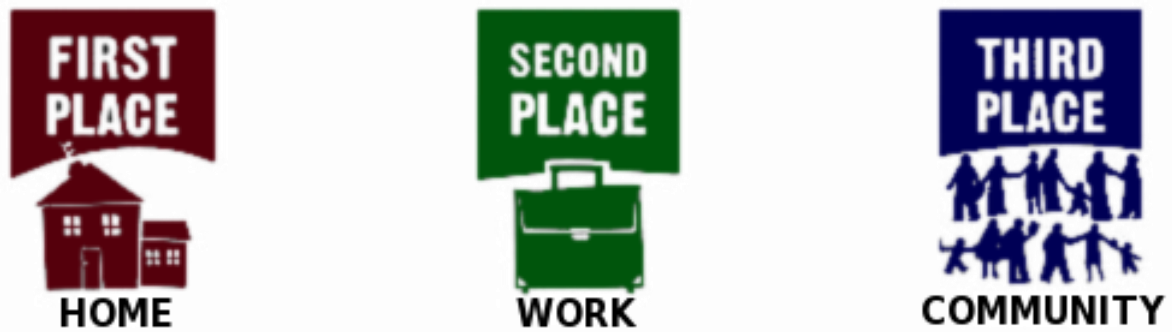

Gambar 2. Third place dalam buku 'The Great Good Place'

Sumber: www.feic.org,2019

Dalam mendesain third place, konsep open architecture akan sangat berpengaruh terhadap interaksi antar individu atau kelompok. Open architecture sangat berkaitan dengan open society dan open city. Open society adalah tempat terbuka dimana tidak adanya perbedaan antar kalangan dan sebagai tempat atau wadah masyarakat dapat setara atau sama. Keterbukaan menjadi poin utama sehingga semua berkumpul, dan berinteraksi satu sama lain. Sedangkan open city, mengacu pada usaha arsitek dan juga urban designer untuk menerjemahkan ide desain dalam merangcang koeksistensi.

Open architecture merupakan system yang terbuka dan mampu beradaptasi dengan kepentingan terpilih. Konflik-konflik dari masyarakat kota dapat dipecahkan atau dilakukan pendekatan melalui rangkaian pendekatan desain (design approach) dan juga strategi perancangan (design strategy).

\section{Urban Farming \\ Definisi Urban Farming}

Urban farming adalah konsep memindahkan pertanian konvensional ke pertanian perkotaan, yang berbeda ada pada pelaku dan media tanamnya. Pertanian konvensional lebih berorientasi pada hasil produksi, sedangkan urban farming lebih pada karakter pelakunya yakni masyarakat urban.

\section{Manfaat Urban Farming}

- Ekonomi

Mampu meningkatkan aktivitas kewirausahaan dan menambah jumlah wiraswasta, meningkatkan lapangan pekerjaan, dan mengurangi angka kemiskinan. Dengan pendeknya rantai pasokan pangan karena dekatnya jarak antara produsen dan konsumen juga mampu mengurangi harga bahan pangan sehingga mengurangi risiko kerawanan pangan di perkotaan. 


\section{- Sosial}

Pertanian urban memiliki dampak secara sosial dan emosional pada setiap orang yaitu dapat berkurangnya tingkat stress dan meningkatnya kesehatan mental karena memiliki kesempatan berinteraksi dengan alam melalui kebun. Pekarangan dan kebun yang terdapat di perkotaan diketahui dapat merelaksasi dan menenangkan, dan memberikan tempat bagi masyarakat untuk beristirahat di kawasan perkotaan yang padat.

- Efisiensi Energi

Sebagai dampak dari berkurangnya penggunaan energi, jejak karbon dari suatu kota akibat usaha pertanian urban juga berkurang. Pertanian urban juga dapat menjadi pembenam karbon (carbon sink) dan sekuestrasi karbon yang mampu menyerap emisi karbon yang umumnya sangat tinggi di perkotaan. Namun usaha ini sangat bergantung pada jenis tanaman, terutama yang tetap berdaun hijau hingga panen. Selain itu pencahayaan dan pengudaraan alami sangat dibutuhkan secara maksimal.

\section{METODE}

Metode yang akan digunakan adalah metode penelitian dengan metode deskriptif yang bertujuan untuk mengumpulkan informasi aktual secara rinci yang melukiskan gejala yang ada, mengidentifikasi masalah atau memeriksa kondisi dan praktek-praktek yang berlaku, membuat perbandingan atau evaluasi dan menentukan apa yang dilakukan orang lain dalam menghadapi masalah yang sama dan belajar dari pengalaman mereka untuk menetapkan rencana dan keputusan pada waktu yang akan datang.

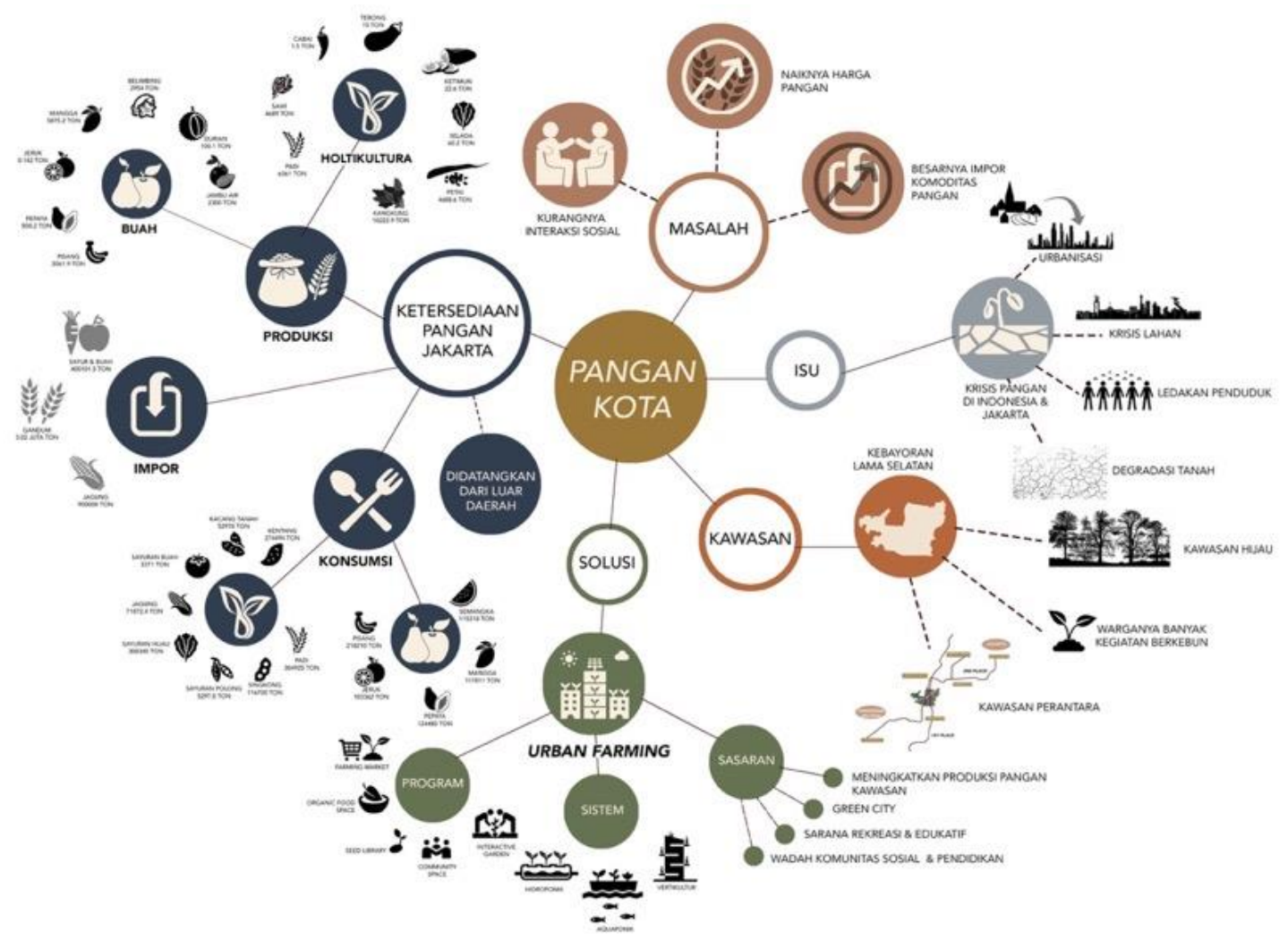

Gambar 3. Skema Berpikir

Sumber: Penulis, 2019

Selain itu, proyek ini juga menggunakan metode 'Urban Analysis' yang menjelaskan analisis makro dari skala urban untuk perancangan yang mempertimbangkan dari aspek urban fabric, linkage, greenbelt, solid void, resident hierarchy dan juga movement. Metode inilah yang menentukan proses pembentukan arsitektur terhadap tapak dan kawasannya. 

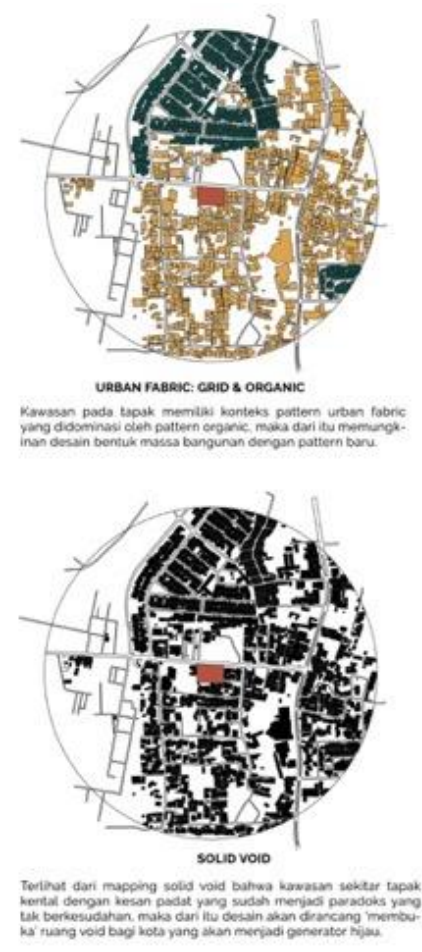

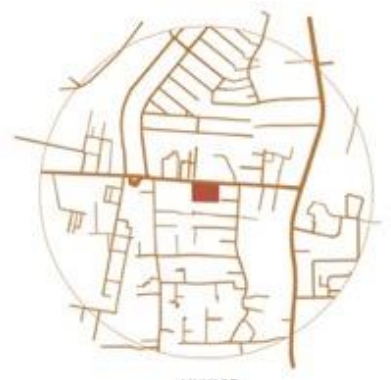

LINKAGE

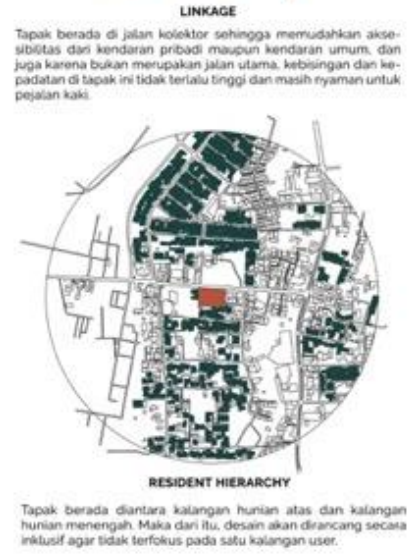

Gambar 4. Urban Analysis

Sumber: Penulis, 2019

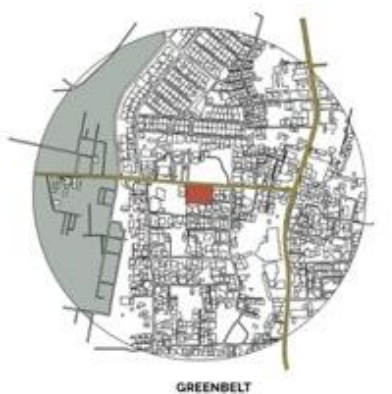

CREENEET
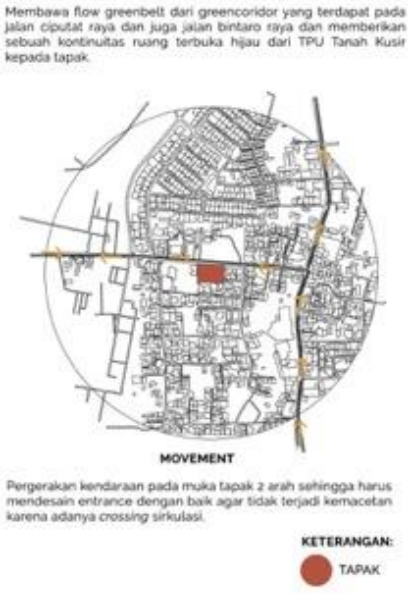

\section{DISKUSI DAN HASIL}

\section{Analisa Kawasan}

- Isu Kawasan

Pemprov DKI Jakarta saat ini sedang mengembangkan adanya ruang ketiga atau 'third place' di kawasan Jakarta Selatan, karena saat ini warga ibu kota membutuhkan ruang terbuka publik atau ruang sosial inklusif yang berfungsi sebagai ruang ketiga untuk mereka setelah rumah dan kantor. Pemprov DKI Jakarta juga menargetkan 160 gang hijau yang dibuat di Jakarta pada tahun 2018, dan di Jakarta Selatan sudah ada 150 titik gang hijau. Target pemerintah pada tahun 2020, setiap RW di 65 kelurahan harus ada gang hijau agar menjadi kota yang sehat. Warga Jakarta Selatan termasuk warga yang paling banyak melakukan kegiatan penghijauan pada pekarangan rumahnya, namun belum semuanya melakukan hal tersebut. Oleh karena itu, third place yang diharapkan di kawasan Kebayoran Lama ini dapat berperan menjadi wadah untuk komunitas agrikultur yang sudah ada agar kebiasaan baik ini dapat terus berkembang di berbagai titik RT RW untuk menjadikan komunitas dan juga kota yang lebih sehat.

- Kondisi Kawasan

Kawasan Kebayoran Lama Selatan terkenal dengan daerah hijaunya, salah satunya yang paling besar yaitu TPU Tanah Kusir. Selain itu, wilayah yang masih rindang terutama di sepanjang jalan raya Kebayoran Lama menjadikan tempat ini cukup asri dan masih hijau guna menyegarkan mata. Karakteristik jalan yang dimiliki Kebayoran Lama raya ini berbeda dengan jalan lainnya dikarenakan model jalan tersebut. Apabila jalan di daerah lain terlampau 'hutan' karena hanya sedikit tersentuh pembangunan, atau kondisi yang ekstrem lainnya terlalu 'gersang' karena terlalu tersentuh pembangunan, situasi di jalan ini merupakan campuran atas keduanya.

- Identifikasi Masalah Kawasan

Kawasan Kebayoran Lama yang terkenal dengan daerah hijaunya, ternyata kelurahan 
Kebayoran Lama Selatan mempunyai kegiatan-kegiatan warga yang memanfaatkan lahan kosong mereka sebagai urban farming. Dari hasil survey yang telah dikumpulkan, ternyata beberapa RW di kelurahan Kebayoran Lama Selatan sudah lama melakukan kegiatan berkebun dan hasilnya ada yang mereka konsumsi sendiri, bahkan sampai dijual. Bukan hanya berkebun saja ditempat ini, ternyata ditempat berkebun ada saung, yaitu tempat dimana warga dapat berkumpul dan berkomunikasi. Namun, kegiatan ini belum ada di setiap RW, dan tidak semua orang mau terlibat dalam kegiatan ini.

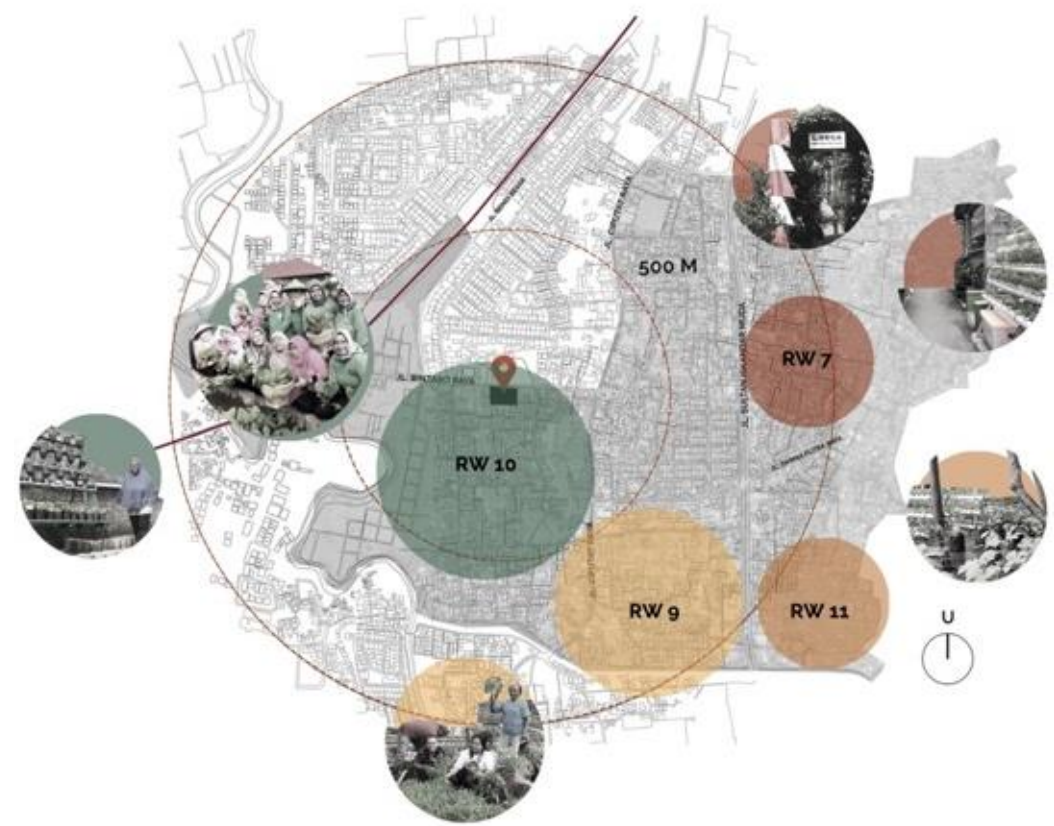

Gambar 5. Pemetaan Kegiatan Urban Farming di Kelurahan Kebayoran Lama Selatan Sumber: Penulis, 2019

\section{Analisa Tapak}

- Lokasi Tapak

\section{SITE INFORMATION}

LOKASI:

Jl. Bintaro Raya No.23. RT 11/RW/10, Kby. Lama Sel, Kec. Kby. Lama. Kota Jakarta Selatan, Daerah Khusus Ibukota Jakarta 12240

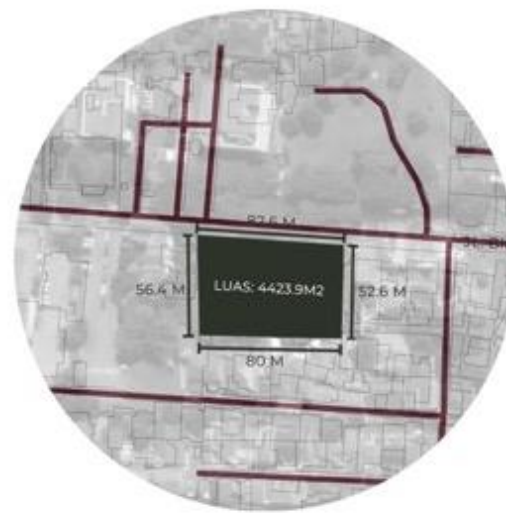

KECAMATAN : KEBAYORAN LAMA KELURAHAN: KEBAYORAN LAMA SELATAN

ZONA : Zona Campuran

KDB SO

$\mathrm{KLB} 2$

KB 4

$\mathrm{KDH} 35$

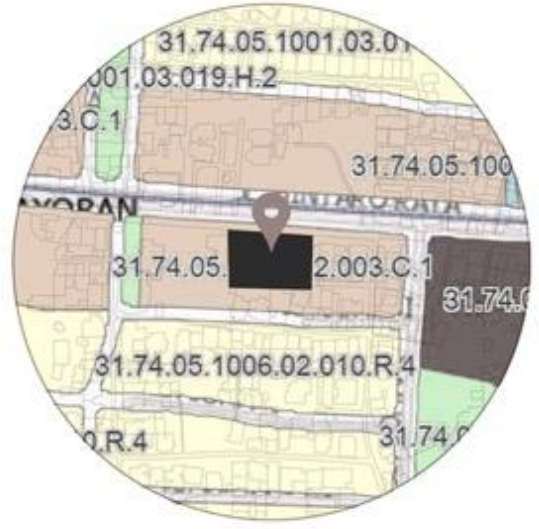

ZONASI:

ZONA CAMPURAN

Gambar 6. Site Information

Sumber: Penulis, 2019 
Gambar diatas menunjukkan keterangan tapak mulai dari alamat tapak, ukuran tapak, luasan tapak, hingga peraturan zonasi tapak. Zonasi tapak berada di zonasi campuran, maka dari itu proyek ini diperbolehkan untuk dibangun di tapak tersebut.

- Akses

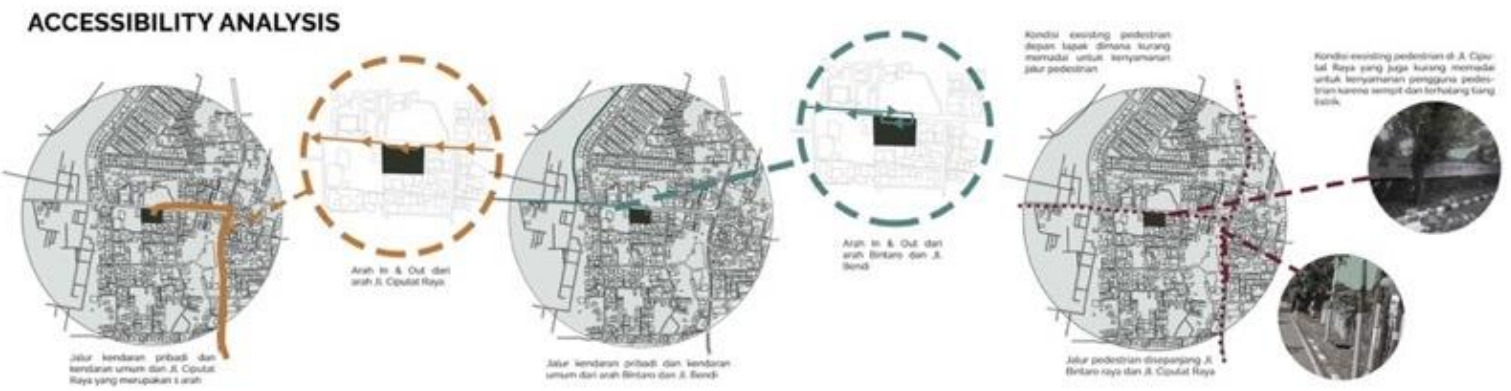

Gambar 7. Accessibility Analysis

Sumber: Penulis, 2019

Gambar diatas adalah analisa aksesibilitas pengendara bermotor terhadap tapak dan juga jalur pedestrian menuju tapak. Hal ini penting untuk menentukan entrance masuk terhadap tapak baik pejalan kaki maupun kendaraan bermotor.

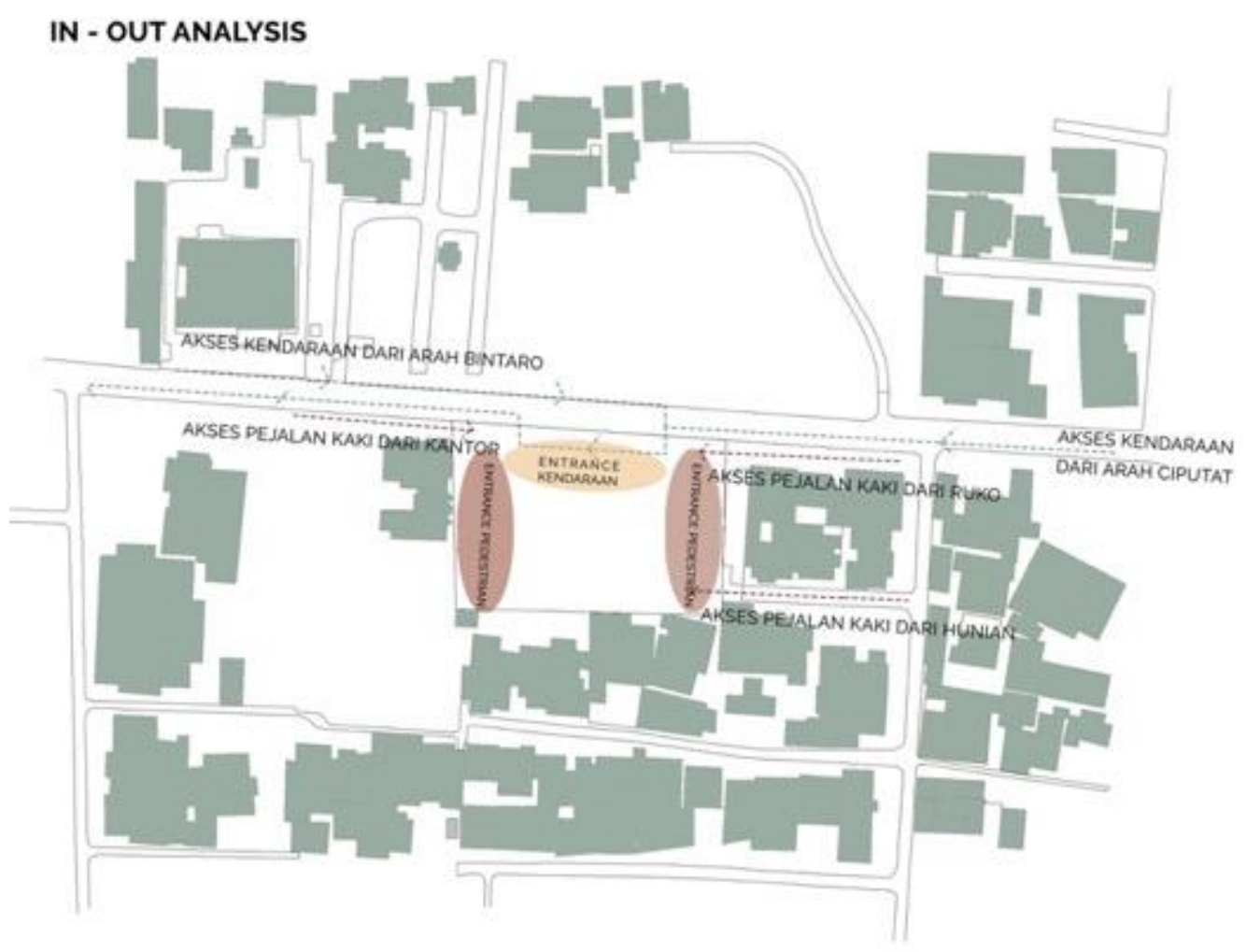

Gambar 8. In-Out Analysis

Sumber: Penulis, 2019

Setelah menganalisa akses, maka dapat ditentukan dimana saja entrance untuk pejalan kaki maupun kendaraan bermotor sehingga tidak terjadinya crossing. 


\section{Skyline Analysis}

SKYLINE ANALYSIS
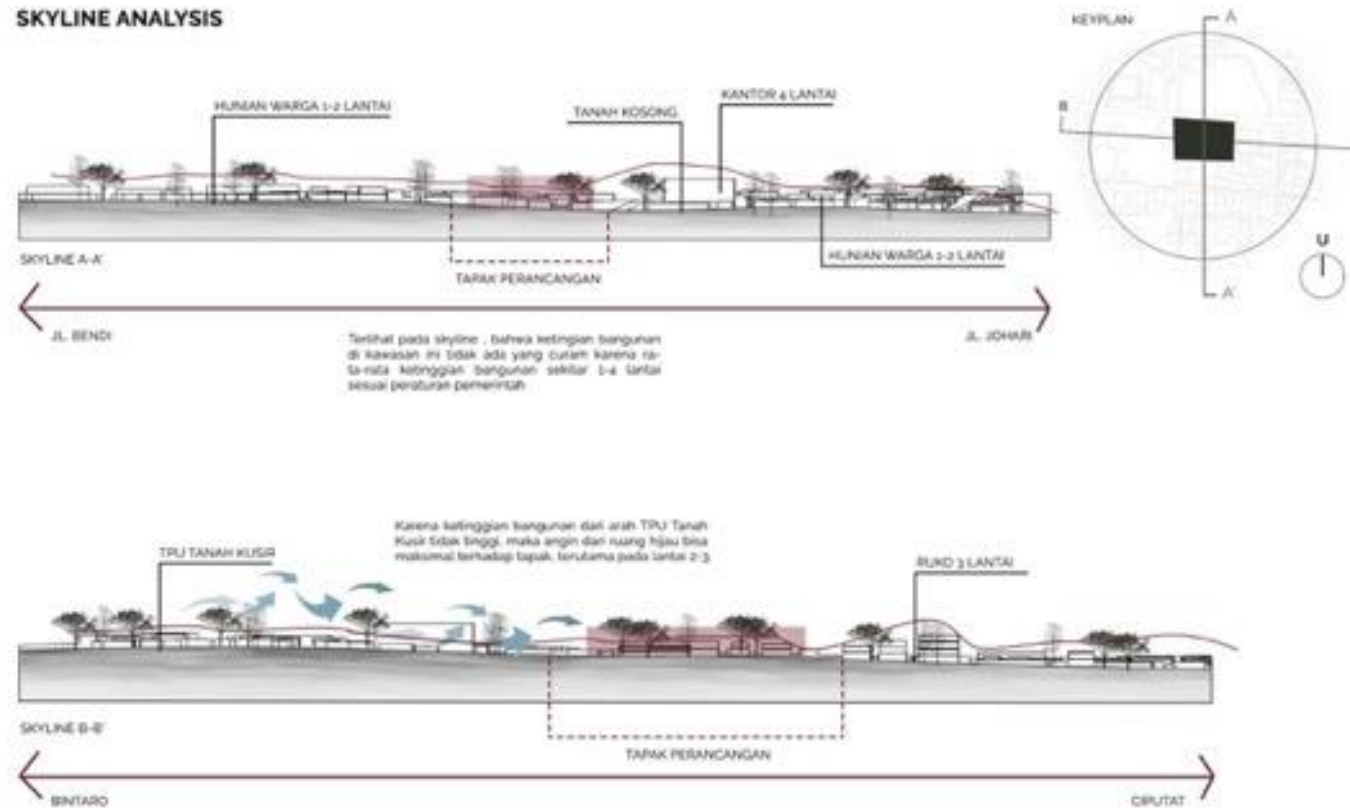

Gambar 9. Skyline Analysis

Sumber: Penulis, 2019

Dari gambar diatas dapat dilihat bahwa ketinggian bangunan di kawasan ini tidak ada yang curam karena rata-rata ketinggian bangunan hanya sekitar 1-4 lantai sesuai peraturan pemerintah. Dan hal ini juga yang membuat arah angin dari ruang terbuka hijau di TPU Tanah kusir dapat mengalir maksimal terhadap tapak.

- View

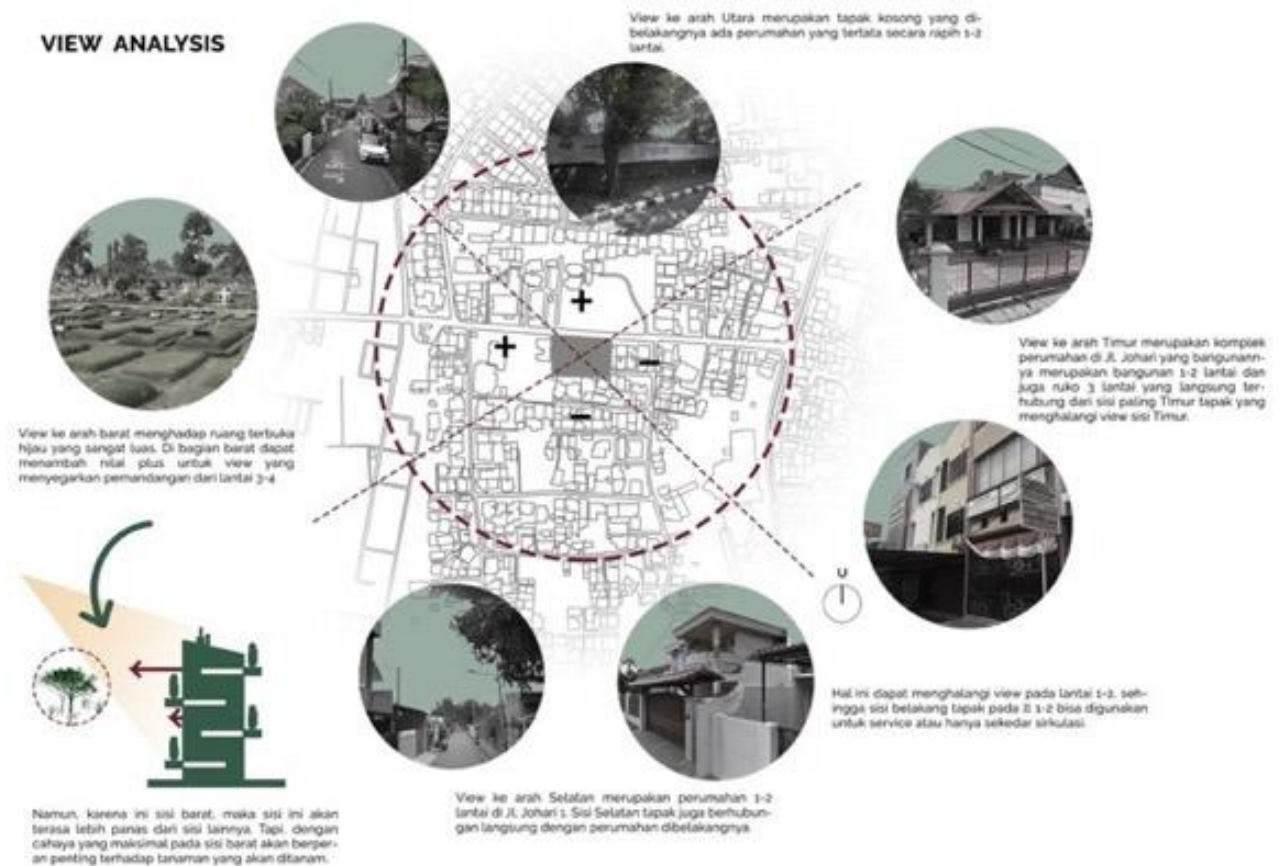

Gambar 10. View Analysis

Sumber: Penulis, 2019 
Dari hasil analisa view, dapat disimpulkan bahwa view ini sangat berperan penting pada orientasi bangunan terhadap jalan di depannya dan juga terhadap entrance untuk mengundang pengunjung terhadap proyek ini. Selain itu, view ini juga sangat penting untuk nilai tambah bagi pengunjung di dalam bangunan untuk melihat secara keseluruhan kawasan disekitarnya.

\section{Deskripsi Desain}

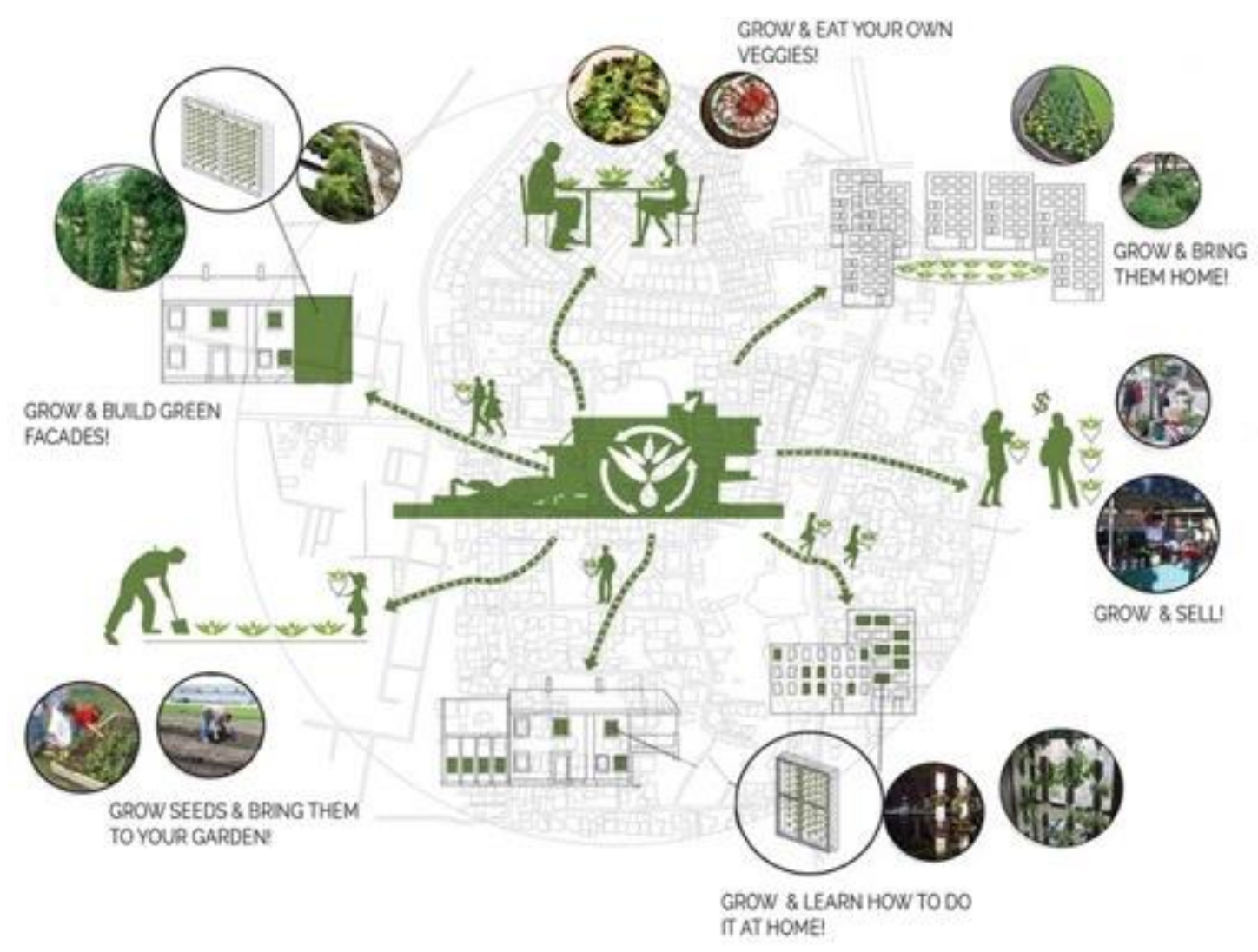

Gambar 11. Program Concept

Sumber: Penulis, 2019

Program pada bangunan ini mengutamakan tentang bagaimana warga di sekitar kawasan dapat memproduksi makanannya sendiri mulai dari langkah kecil yaitu menanam makanan sehari-hari seperti sayuran dan juga buah-buahan. Dalam proyek ini diharapkan warga bisa mempraktikkan cara membuat dan mengelola tanaman yang akan dikonsumsi dirumah masing-masing dan juga bisa memproduksi hasil sayuran yang baik sehingga selain dikonsumsi sendiri, hal ini juga bisa menjadi bidang usaha bagi warganya. Proyek ini membantu warga sekitar agar menambah pasokan pangan bagi kawasan dan juga mengedukasi warganya untuk hidup sehat sekaligus produktif.

\section{Konsep Perancangan}

- Gubahan Massa

Gambar dibawah ini menjelaskan bagaimana proses desain dari bangunan menurut analisa tapak dan juga lingkungan sehingga menghasilkan bentuk seperti gambar diatas. Proses desain inilah yang akan menjadi acuan untuk proses desain selanjutnya. 


\section{DESIGN SCHEME}

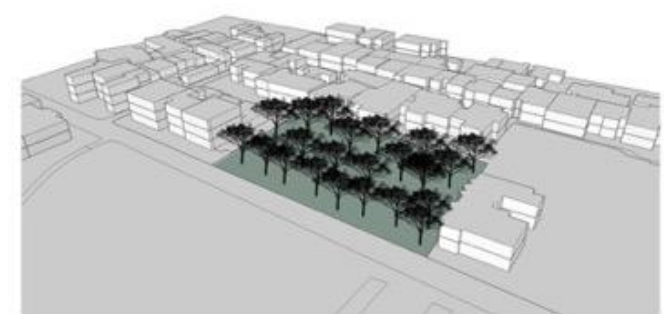

Kondisi existing tapak yang berupa tanah kosong penuh dengan penghijauan

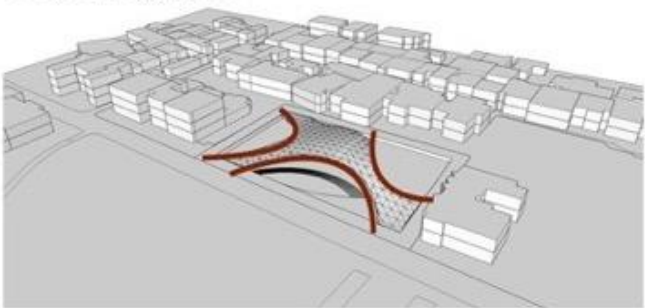

Penggunaan sunken untuk ruang publik yang lebih nyaman dan tidak terganggu dengan kendaraan bermotor karena tapak yang berada dipingir jalan raya. Hal in juga menciptakan kesan 'openness' pada bangunan.

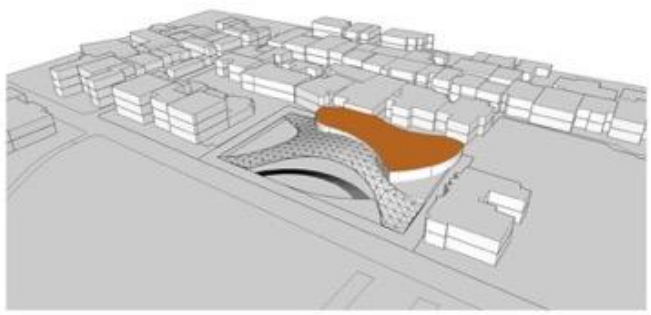

Penambahan massa untuk kegiatan edukasi untuk menunjang kegiatan urban farming dan juga pengelola management bangunan.

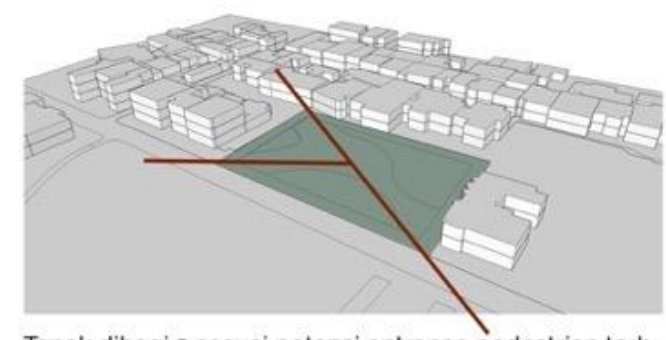

Tapak dibagi 3 sesuai potensi entrance pedestrian terhadap tapak.

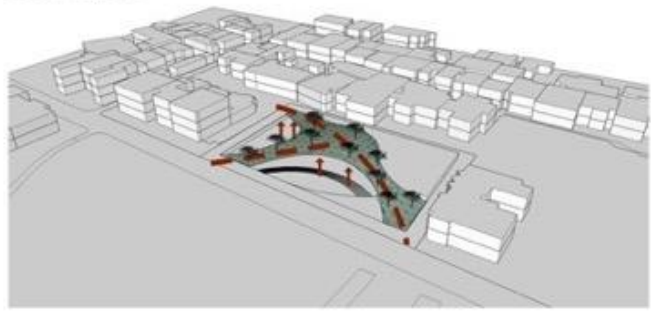

Landscape existing dinaikan sebagai bentuk adaptas dari ruang terbuka hijau dan menciptakan fleksibilitas dalm bangunan.

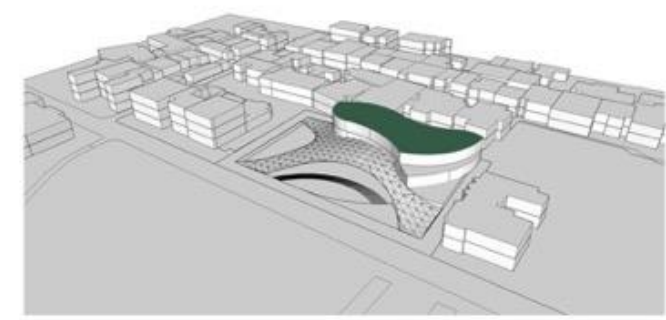

Atap akan difungsikan sebagai kegiatan urban farming agar konsep hiijau di bangunan ini menyatu untuk keseluruhan bangunan.

\section{Gambar 12. Design Scheme}

Sumber: Penulis, 2019

\section{- Green Concept}

Gambar dibawah ini menjelaskan konsep hijau dari proyek ini. Dengan beberapa poin penting perancangan seperti greenroof, greenfacade, sunken semi basement, rain garden, dan zero run-off akan mengurangi penggunaan energi buatan dari segi cahaya, udara, maupun listrik pada bangunan. Sehingga bangunan ini akan mencapai konsep berkelanjutan. Begitu juga dengan komponen vegetasi yang akan memperkuat konsep hijau bagi bangunan 


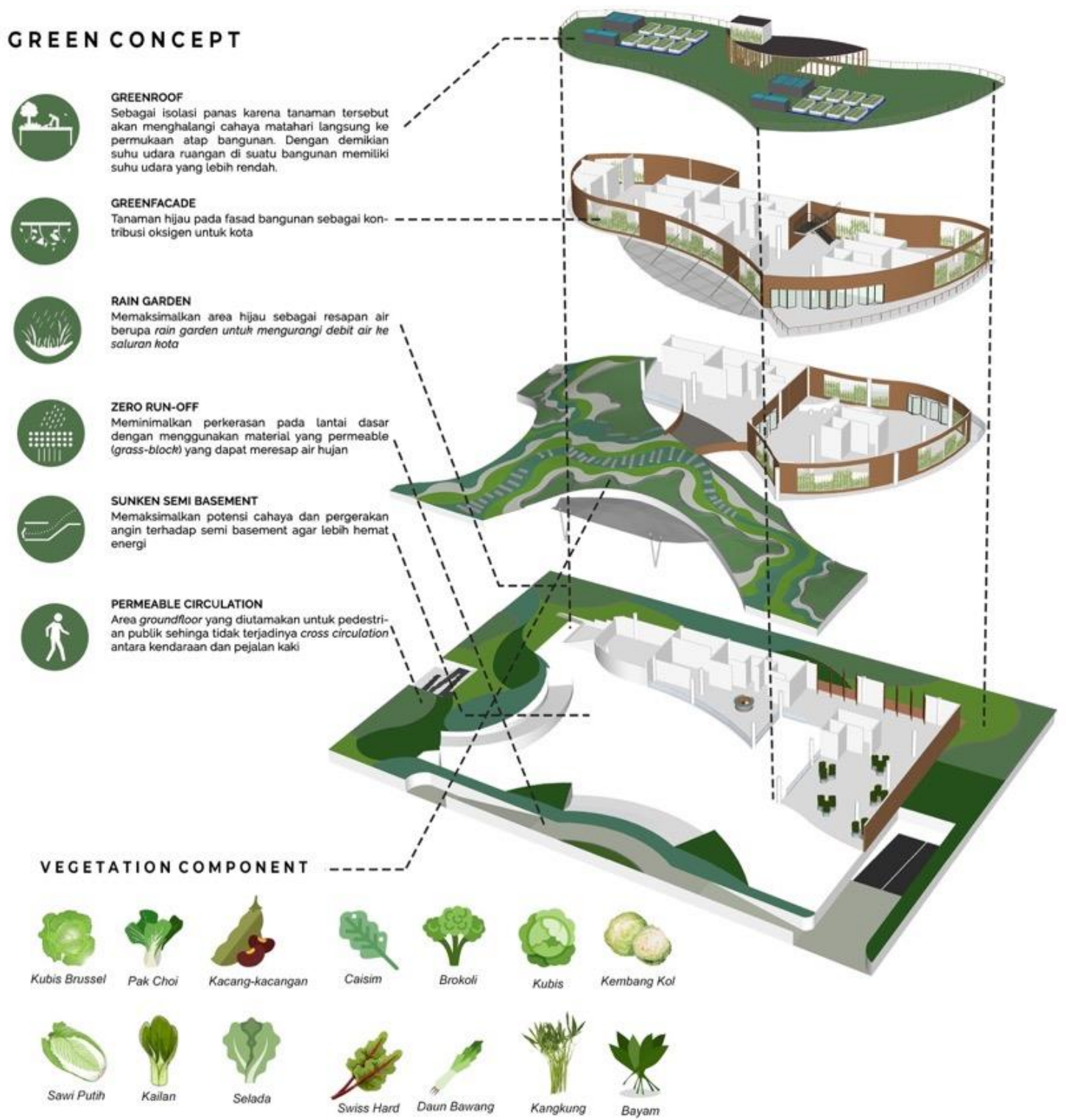

Gambar 13. Green Concept Sumber: Penulis, 2019

\section{Hasil Perancangan}

- Denah Exploded dan Sirkulasi

Gambar dibawah ini menunjukkan program apa saja yang ada pada setiap lantainya, dan juga sirkulasi pengelola, service dan juga pengunjung. Pada lantai basement digunakan untuk area parkir dan juga service, untuk lantai lower ground dan ground floor sebagai area komersil dan entertainment, pada lantai $2 \& 3$ sebagai area edukasi dan lantai rooftop sebagai area hijau atau area tanam hidroponik. 


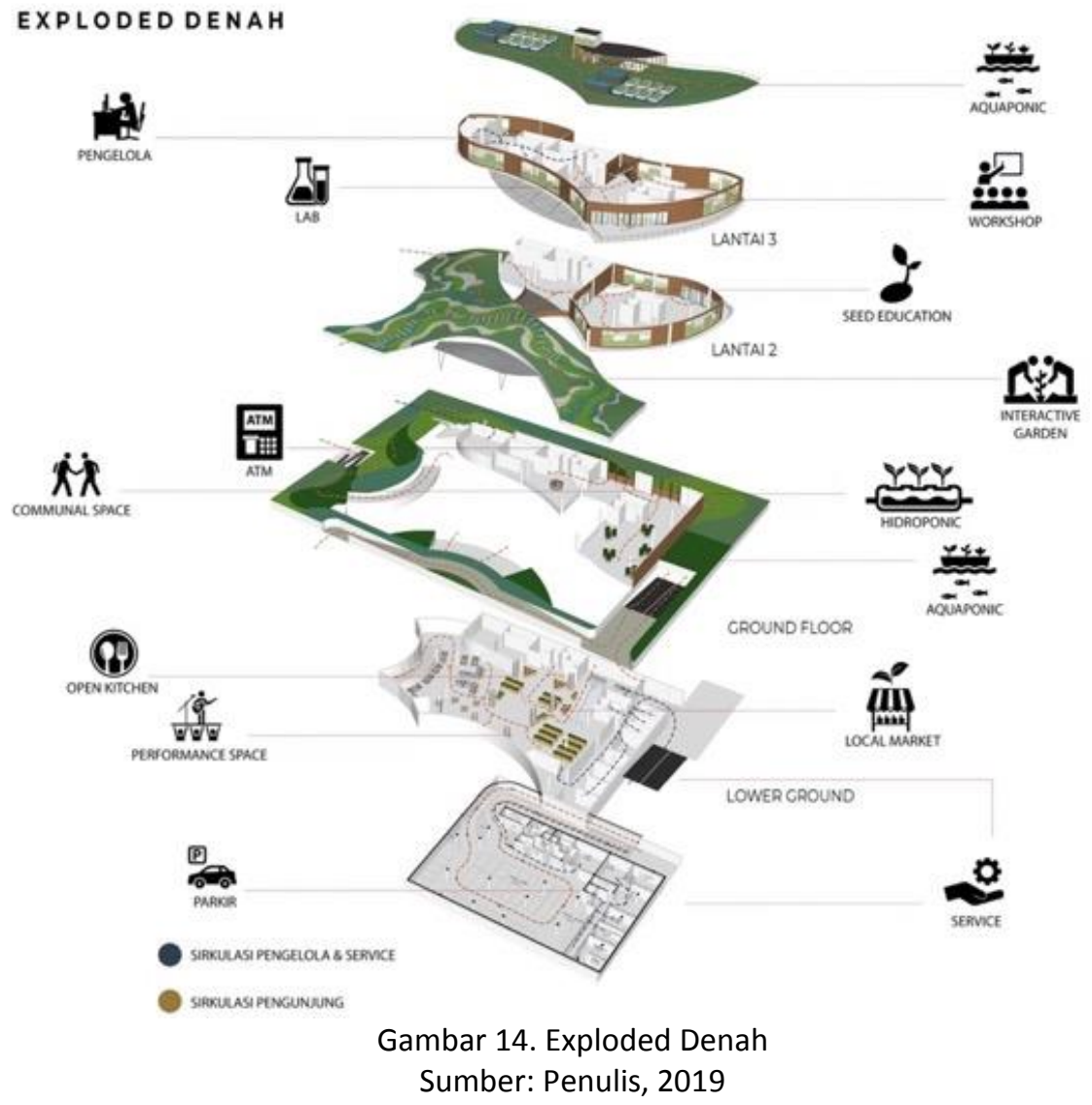

Tampak dan Potongan
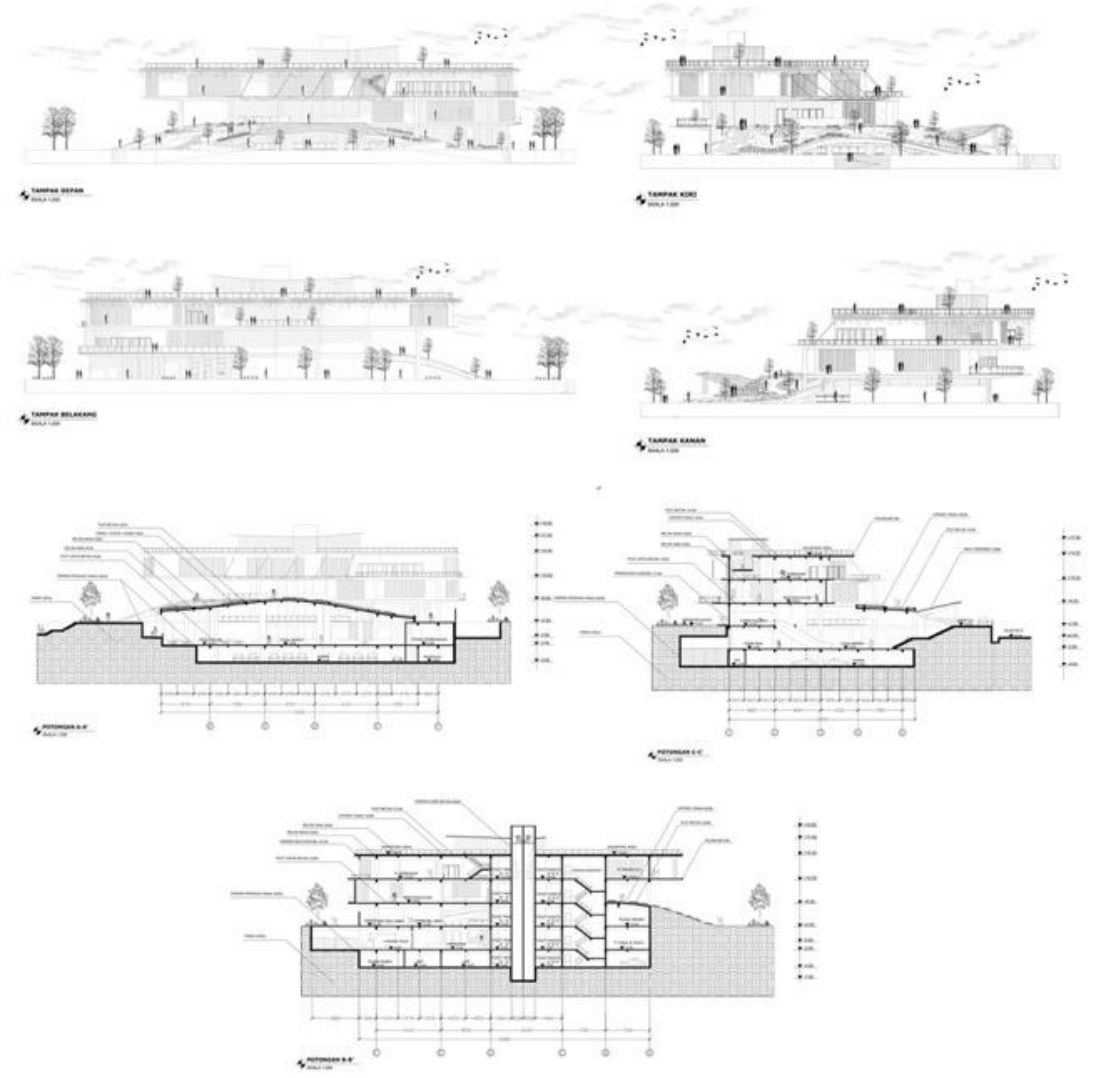

Gambar 15. Tampak \& Potongan

Sumber: Penulis, 2019 


\section{KESIMPULAN}

Proyek ini memberikan ruang hijau dan rekreasi, memberikan penghematan dan manfaat ekologis bagi kota, membantu pembentukkan komunitas dan memiliki potensi sebagai sumber baru pembangunan ekonomi. Karena terbatasnya lahan pertanian di Jakarta, terbatasnya jumlah produksi pangan di Kota Jakarta yang tidak sebanding dengan jumlah penduduk, Jakarta tidak mampu memenuhi konsumsi warganya, sehingga proyek ini dapat membantu permasalahan tersebut dengan program 'urban farming'.

Dengan kawasan yang mempunyai nilai tambah dengan kawasan hijaunya dan juga penduduk yang senang berkebun, maka dari itu proyek ini dapat membantu perkembangan dari potensi kawasan itu sendiri. Dari segi ekonomi, proyek ini juga dapat membantu fasilitasfasilitas di sekitarnya karena dapat mendistribusi pangan ke tempat perbelanjaan dan mengurangi adanya kenaikan harga pangan. Selain itu, diharapkan proyek ini dapat melebur dalam konteks kota yang lebih luas dan menjadi keseharian dan budaya baru bagi masyarakat kota.

\section{SARAN}

Program seperti ini disarankan untuk menjadi program pemerintah di perkotaan terutama Jakarta yang kekurangan pasokan pangan sehingga dapat memenuhi kebutuhan warga sekitarnya dan juga dapat menambah lapangan pekerjaan baru untuk masyarakat. Selain itu, dapat juga membantu kota agar lebih berkelanjutan dengan memperbanyak tenaga ahli di bidang pertanian.

\section{REFERENSI}

Archipelago (2017). Archipelago Vol.2 : Ruang Produktif Pangan. Jakarta

Birkby, Jeff (2016). Vertical Farming. Dalam publikasi Appropiate Technology Transfer for Rural Area. Amerika. National Center for Appropriate Technology.

BPS (2019). Produksi Tanaman Bahan makanan 2009-2013 dari BPS: https://jakarta.bps.go.id/statictable/2015/04/10/39/produksi-tanaman-bahan-makanan2009-2013.html

Butler, L. and D.M. Moronek (eds.) (2002). "Urban and Agriculture Communities: Opportunities for Common Ground". Ames, lowa: Council for Agricultural Science and Technology. Diakses tanggal 2013-04-01.

Conway C. \& Barbier, E.G. (1990). After the green revolution: sustainable agriculture for development. London: Earthscan Publications Ltd.

Creative Commons (2019). Data Farming: Demonstrating the Benefits of Urban Agriculture http://thisbigcity.net/data-farming-demonstrating-the-benefits-of-urban-agriculture/Food and Agriculture Organization of the United Nations. (2015). Cities of despair - or opportunity?. United Nation

Fraser, E. D.G. (2002). "Urban Ecology in Bangkok Thailand: Community Participation, Urban Agriculture and Forestry," Environments 30 (1).

Gips, T. (1986). What is Sustainable Agriculture? In: Allen, $P$ and Van Dusen, D.(eds.) Global Perspective in Agroecology and Sustainable Agricultural System: Proceeding of the $6^{\text {th }}$ International Scientific Conference of The International Federation of Organic Agriculture Movements (IFOAM). Amerika: University of California, Santa Cruz.

Industry Dive. (2019) Data Farming: Demonstrating the Benefits of Urban Agriculture https://www.smartcitiesdive.com/ex/sustainablecitiescollective/data-farmingdemonstrating-benefits-urban-agriculture/133921/

Kementrian Perindustrian. (2018). Making Indonesia 4.0. Jakarta: Kementrian Perindustrian. Manguiat IJ. (1995). In Search of Alternative Fertilizers for Sustainable Agriculture: The Sestania Option. Philippines: SEAMEO-SEARCA, Los Banos. 
Ningrum V. (2017). Krisis Pangan Ancam Indonesia. Retrieved August 14, 2019, from http://lipi.go.id/lipimedia/krisishttp://lipi.go.id/lipimedia/krisis-pangan-ancamindonesia/19061pangan-ancam-indonesia/19061

Oldenburg, R. (1989). The Great Good Place. Da Capo Press : Cambridge.

Penn, J.B., Ronald D. Knutson, dan Barry L. Flinchbaugh. (2006). Agricultural and Food Policy. New-Jersey: Prentice Hall PTR

Piesse, M. (2016). Food Security in Indonesia a Continued Reliance on Foreign Markets. Retrieved August 14, 2019, from http://www.futuredirections.org.au/publication/foodsecurity-in-indonesia-ahttp://www.futuredirections.org.au/publication/food-securityin-indonesia-a-continued-reliance-on-foreign-markets/continued-reliance-on-foreignmarkets/

Ruaf. Urban Agriculture: What and Why?. Retrieved August 20, 2019, from https://www.ruaf.org/urbanhttps://www.ruaf.org/urban-agriculture-what-andwhyagriculture-what-and-why

Soekartawi. (1995). Analisis Usaha Tani. Jakarta : UI Press.

Smit, J., A. Ratta, and J. Nasr. (1996). Urban Agriculture: Food, Jobs, and Sustainable Cities. United Nations Development Programme (UNDP), New York, NY.

Thornton, A. (2011) Food for thought? The potential of urban agriculture in local food production for food security in the South Pacific. In Campbell, H. Rosin, C. and Stock, P. (eds) Dimensions of the Global Food Crisis. London: Earthscan. Pg 200-218. 